\title{
NOMENCLATURE
}

\section{GENERAL COMMITTEE REPORT, 1972}

The General Committee has approved Report XV of the Committee for Spermatophyta (Taxon 21:531-535. 1972). The names therein recommended for conservation may thus be used under Art. 15, pending final approval by the Leningrad Congress.

The General Committee was asked for an opinion, under Article 75, regarding the generic names Acantboica Lohmann and Acantboeca W. Ellis, both applying to phytoflagellate algae. Fifteen members of the Committee voted, and they were unanimous in considering that these two names are sufficiently alike to be considered homonyms.

The Committee was also asked for an opinion on the generic names Conostomum Swartz (Musci) and Conostoma Williamson (a Paleozoic Pteridosperm ovule). Seventeen members voted, of whom 3 considered the names homonymous and 14 considered that they were not sufficiently alike to be confused. [The Secretary notes that there also exists a generic name Conostomium (Stapf) Cufodontis, in the Rubiaceae.]

Opinions were also sought from the Committee regarding the generic names Mooria and Ballardia (both in the Myrtaceae). On Mooria Montrouzier vs. Moorea Lemaire (Gramineae), 11 of the 17 members voting considered the names homonyms, and 6 did not. On Ballardia Montrouzier vs. Balardia Cambessedes (Caryophyllaceae), 12 members considered the names homonyms and 5 did not.

In a more complex matter, the General Committee was asked for advice regarding a possible instance of "misplaced terms" (Art. 33), being informed that Loudon (Arboretum et Fruticetum 4: 2152-2292. 1838) gathered the species of Pinus in three or more levels of infrageneric categories, two of which were called sections and were named and described; e.g., section Binae was divided into sections Sylvestres, Laricio, Pinaster, and Halepenses. The question was whether the names at both levels were validly published or, if Articles 5 and 33 were violated, whether names at both levels were invalid or only one of them; and finally, whether the subordinate or secondary "sections" are correctly to be interpreted and treated as subsections. Sixteen members of the General Committee voted. Of these, only two held that neitber level of Loudon's "sections" was validly published. One member held that Loudon's secondary "sections" (identified by the symbol $\$$ and with "Sect. Char." described) were validly pubilshed both as sections and as subsections but that Loudon's primary "sections" were not validly published at all. The other 13 members who voted all held that Loudon's primary "sections" were validly published. Five of these, however, apparently felt that the secondary "sections" were not validly published in any rank; the other 8 members held that they were validly published as subsections even though some expressed reservations: one member added the comment that "section" was being used as an ordinary word, not a taxonomic rank, in this position; another added that an addition to the Code is required; and another pointed out that in his introduction, Loudon (p. 2150) referred to "the group Sylvestres, of the section Binae."

E. G. Voss, Secretary*

* Herbarium, North University Bldg., The University of Michigan, Ann Arbor, Michigan 48104 , U.S.A. 